\title{
Underestimation of the incidence of new-onset post-coronary artery bypass grafting atrial fibrillation and its impact on 30-day mortality
}

\author{
Giovanni Filardo, PhD, MPH, ${ }^{\mathrm{a}, \mathrm{b}}$ Benjamin D. Pollock, MSPH, ${ }^{\mathrm{a}}$ Briget da Graca, JD, MS, ${ }^{\mathrm{a}}$ \\ Teresa K. Phan, MS, MS, ${ }^{\mathrm{a}}$ Danielle M. Sass, MPH, CPH, ${ }^{\mathrm{a}}$ Gorav Ailawadi, MD, ${ }^{\mathrm{c}}$ Vinod Thourani, MD, ${ }^{\mathrm{d}}$ and \\ Ralph Damiano, MD
}

\begin{abstract}
Objective: Inconsistent definitions of atrial fibrillation after coronary artery bypass grafting have caused uncertainty about its incidence and risk. We examined the extent to which limiting the definition to post-coronary artery bypass grafting atrial fibrillation events requiring treatment underestimates its incidence and impact on 30-day mortality.
\end{abstract}

\begin{abstract}
Methods: We assessed in-hospital atrial fibrillation and 30-day mortality in 9268 consecutive patients without preoperative atrial fibrillation who underwent isolated coronary artery bypass grafting at 5 US hospitals (2004-2010). Patients who experienced 1 or more episode of post-coronary artery bypass grafting atrial fibrillation detected via continuous in-hospital electrocardiogram/telemetry monitoring were divided into those for whom Society of Thoracic Surgeons data (applying the definition "atrial fibrillation/flutter requiring treatment") also indicated atrial fibrillation versus those for whom it did not. Risk-adjusted 30 -day mortality was compared between these 2 groups and with patients without post-coronary artery bypass grafting atrial fibrillation.
\end{abstract}

Results: Risk-adjusted incidence of post-coronary artery bypass grafting atrial fibrillation incidence was 33.4\% (27.0\% recorded in Society of Thoracic Surgeons data, $6.4 \%$ missed). Patients with post-coronary artery bypass grafting atrial fibrillation missed by Society of Thoracic Surgeons data had a significantly greater risk of 30-day mortality (odds ratio, 2.08, 95\% confidence interval, 1.17-3.69) than those captured. By applying the significant underestimation of post-coronary artery bypass grafting atrial fibrillation incidence we observed (odds ratio [Society of Thoracic Surgeons vs missed], 0.78 ; $95 \%$ confidence interval, $0.72-0.83$ ) to the approximately 150,000 patients undergoing isolated coronary artery bypass grafting in the United States each year estimates this increased risk of mortality is carried by 9600 patients (95\% confidence interval, 9420-9780) annually.

Conclusions: Defining post-coronary artery bypass grafting atrial fibrillation as episodes requiring treatment significantly underestimates incidence and misses patients at a significantly increased risk for mortality. Further research is needed to determine whether this increased risk carries over into long-term outcomes and whether it is mediated by differences in treatment and management. ( $\mathrm{J}$ Thorac Cardiovasc Surg 2017;154:1260-6)

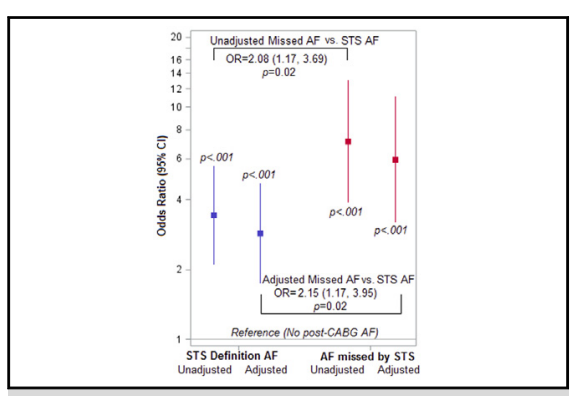

Unadjusted and adjusted ${ }^{*}$ ORs for operative mortality. ${ }^{*}$ Adjusted for the STS risk of mortality and time of surgery.

\section{Central Message}

The STS definition of post-CABG AF significantly underestimates incidence, missing approximately 9600 US patients each year who are at significantly increased risk for 30 day mortality.

\section{Perspective}

The association between post-CABG AF and poor survival is well known, but the definition has not been standardized to ensure all patients at risk are identified. The STS data (AF/flutter requiring treatment) miss approximately 9600 US patients with new-onset $\mathrm{AF}$ after isolated CABG annually; our results show they carry an unrecognized significantly increased risk for 30-day mortality.

See Editorial Commentary page 1267.

\footnotetext{
From the a Office of the Chief Quality Officer, Baylor Scott \& White Health, Dallas, Tex; ${ }^{\mathrm{b}}$ The Heart Hospital Baylor Plano, Plano, Tex; ${ }^{\mathrm{c}}$ Division of Thoracic and Cardiovascular Surgery, University of Virginia, Charlottesville, Va; ${ }^{\mathrm{d}}$ Division of Cardiothoracic surgery, Emory University, Atlanta, Ga; and ${ }^{\mathrm{e} D e p a r t m e n t}$ of Cardiac Surgery, Washington University School of Medicine and Barnes-Jewish Hospital, St Louis, Mo.

This work was funded by the National Institutes of Health/National Heart, Lung, and Blood Institute (R01HL103683) and in part by the Bradley Family Endowment to the Baylor Health Care System Foundation and the Baylor Health Care System Cardiovascular Research Committee.
}

Received for publication Nov 1, 2016; revisions received May 15, 2017; accepted for publication May 24, 2017; available ahead of print July 8, 2017.

Address for reprints: Giovanni Filardo, PhD, MPH, Office of the Chief Quality Officer, Baylor Scott \& White Health, 8080 North Central Expressway, Suite 900, Dallas, TX 75206 (E-mail: giovanfi@baylorhealth.edu). $0022-5223 / \$ 36.00$

Copyright (C) 2017 by The American Association for Thoracic Surgery http://dx.doi.org/10.1016/j.jtcvs.2017.05.104 


$$
\begin{aligned}
& \text { Abbreviations and Acronyms } \\
& \begin{aligned}
\text { AF } & =\text { atrial fibrillation } \\
\text { CABG } & =\text { coronary artery bypass grafting } \\
\text { CI } & =\text { confidence interval } \\
\text { ECG } & =\text { electrocardiogram } \\
\text { GEE } & =\text { generalized estimating equation } \\
\text { OR } & =\text { odds ratio } \\
\text { STS } & =\text { Society of Thoracic Surgeons }
\end{aligned}
\end{aligned}
$$

Scanning this QR code will take you to the article title page.

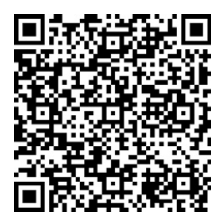

Development of atrial fibrillation (AF) after cardiac surgery was considered a minor, self-limiting complication until relatively recently. ${ }^{1-5}$ Approximately a decade ago, however, evidence started emerging that it was independently associated with poorer survival after coronary artery bypass grafting $(\mathrm{CABG}){ }^{2,3,6-9}$ It is now recognized as a serious complication, and practice guidelines and quality measures have been introduced related to its prevention. ${ }^{10-13}$ However, no standard definition has been established to ensure all patients who carry this risk for poor outcomes are identified for follow-up and management after discharge. Research studies to date have used a wide variety of definitions and means of detecting $\mathrm{AF},{ }^{14,15}$ creating uncertainty about its true incidence and how effectively the risks it is associated with are being managed.

The Society of Thoracic Surgeons (STS) Adult Cardiac Surgery Database incorporates data from approximately $95 \%$ of the cardiac surgery programs in the United States, ${ }^{16}$ making it and the regional STS-certified databases built around the same routinely collected data valuable resources for studies investigating postoperative $\mathrm{AF},{ }^{17-19}$ and therefore influential in determining the definition of postoperative $\mathrm{AF}$ on which the evidence base regarding its prevention and management will be built. Currently, the STS defines postoperative AF as "atrial fibrillation/ flutter requiring treatment." ${ }^{20}$ Because there are no criteria for the determination of when treatment is required, this is an ambiguous definition, subject to the vagaries of differing indications for treatment between physicians and hospitals, and may substantially underestimate the incidence of postoperative $\mathrm{AF}$, and, thus, the patients at risk for late mortality. Given the clinical significance, the question arises as to whether the STS definition needs to be updated and refined.
To address this question, we used data from a large, multicenter observational study to compare the riskadjusted incidence of new-onset post-CABG AF defined according to the STS data and definition versus any episode detected via continuous in-hospital electrocardiogram (ECG)/telemetry monitoring and documented by a physician in the patient's chart, regardless of duration or need for treatment, but not captured in the STS data. We then compared 30-day mortality between these 2 groups and patients who did not develop AF to determine whether the difference in definition is clinically meaningful.

\section{MATERIALS AND METHODS \\ Patients and Setting}

This multicenter observational study was conducted in 9268 consecutive patients without a history of AF who underwent isolated CABG between January 1, 2004, and December 31, 2010, at Baylor University Medical Center (Dallas, Tex), The Heart Hospital Baylor Plano (Plano, Tex), Emory University (Atlanta, Ga), University of Virginia (Charlottesville, Va), or Washington University (St Louis, Mo). Patients were excluded if they had preoperative endocarditis or a ventricular assist device. The study was approved by the institutional review boards of all participating centers.

\section{Data Collection and Outcome Measures}

Data regarding patient and operative characteristics routinely collected for the STS database were augmented with detailed data regarding AF events abstracted from medical records, based on ECG findings.

The outcome measures were the adjusted incidence of new-onset postCABG AF defined as (1) AF/flutter requiring treatment (AF identified in the STS data $)^{20}$ and (2) any episode detected via continuous in-hospital ECG/telemetry monitoring and documented by a physician in the patient's chart, regardless of duration or need for treatment, but not recorded in the STS data (AF not identified in the STS data). Mortality at 30 days postsurgery was assessed using the vital status information contained within the STS data and compared between the patients with these 2 definitions of post-CABG AF and the patients without post-CABG AF.

\section{Statistical Analysis}

The overall adjusted incidence of new-onset post-CABG AF (including all patients with any episode detected via continuous in-hospital ECG/ telemetry monitoring and documented by a physician in the patient's chart, regardless of whether it was also captured in the STS data) was assessed with a generalized estimating equation (GEE) model approach to account for patient and site variability. The GEE model was adjusted for the STS risk of mortality ${ }^{21}$ and time of operation (incremental month starting from January 2004 [month 1] to December 2010 [month 84]). All continuous covariates were modeled with a 5-knot restricted cubic spline. ${ }^{22,23}$ The same model, with the addition of the interaction between AF definition and time of operation, was used to compare the adjusted incidence of new-onset post-CABG AF according to whether or not the patient's AF was identified in the STS data. Model estimates were used to compute the adjusted new-onset post-CABG AF incidences, odds ratios (ORs), 95\% confidence intervals (CIs), and $P$ values.

The impact of limiting the definition of post-CABG AF to events requiring treatment on the detection of new-onset $\mathrm{AF}$ in the US population undergoing isolated CABG was estimated by applying the risk-adjusted difference in incidence between patients whose AF events were versus were not identified in the STS data in our study population to the total number of isolated CABG procedures performed in the United States 
TABLE 1. Patient characteristics by new-onset post-coronary artery bypass grafting atrial fibrillation incidence

\begin{tabular}{|c|c|c|c|}
\hline \multirow[b]{2}{*}{ Characteristic } & \multicolumn{2}{|c|}{ Post-CABG AF* } & \multirow{2}{*}{$\begin{array}{c}\text { No post-CABG AF } \\
6627(71.5 \%)\end{array}$} \\
\hline & $\begin{array}{c}\text { AF identified in STS data } \dagger \\
2204(23.8 \%)\end{array}$ & $\begin{array}{c}\text { AF not identified in STS data* } \\
\qquad 437(4.7 \%)\end{array}$ & \\
\hline \multicolumn{4}{|l|}{ Study site (row \%) } \\
\hline Baylor $\ddagger$ & $1051(26.7)$ & $219(5.6)$ & $2671(67.8)$ \\
\hline Emory & $448(19.6)$ & $116(5.1)$ & $1726(75.4)$ \\
\hline University of Virginia & $281(13.8)$ & $54(2.6)$ & 1708 (83.6) \\
\hline Washington University & $424(30.3)$ & $48(3.4)$ & $929(66.3)$ \\
\hline Age - mean \pm SD & $67.7 \pm 9.3$ & $66.5 \pm 10.4$ & $61.3 \pm 10.6$ \\
\hline BMI, $\mathrm{kg} / \mathrm{m}^{2}$ - mean $\pm \mathrm{SD}$ & $29.6 \pm 7.1$ & $30.2 \pm 7.3$ & $29.4 \pm 5.8$ \\
\hline Male & $1680(76.2)$ & $324(74.1)$ & $4786(72.2)$ \\
\hline Female & $524(23.8)$ & $113(25.9)$ & $1841(27.8)$ \\
\hline \multicolumn{4}{|l|}{ Race } \\
\hline White & $1884(85.5)$ & $356(81.5)$ & $5097(76.9)$ \\
\hline Black & $197(8.9)$ & $53(12.1)$ & $1005(15.2)$ \\
\hline Hispanic & $65(2.9)$ & $12(2.7)$ & $248(3.7)$ \\
\hline Asian & $30(1.4)$ & $7(1.6)$ & $129(1.9)$ \\
\hline Other & $28(1.3)$ & $9(2.1)$ & $148(2.2)$ \\
\hline Diabetes mellitus & $919(41.7)$ & $200(45.8)$ & $2681(40.5)$ \\
\hline Renal failure & $67(3.0)$ & $18(4.1)$ & $191(2.9)$ \\
\hline Creatinine $(\mathrm{mg} / \mathrm{dL})-$ mean $\pm \mathrm{SD}$ & $1.3 \pm 1.1$ & $1.3 \pm 1.3$ & $1.2 \pm 1.2$ \\
\hline Chronic lung disease & $543(24.6)$ & $96(22.0)$ & $624(9.4)$ \\
\hline Systemic hypertension & $1931(87.6)$ & $387(88.6)$ & $5687(85.8)$ \\
\hline Peripheral vascular disease & $534(24.2)$ & $89(20.4)$ & $1173(17.7)$ \\
\hline Cerebrovascular disease & $453(20.6)$ & $85(19.5)$ & $1041(15.7)$ \\
\hline \multicolumn{4}{|l|}{ Time from last myocardial infarction to surgery } \\
\hline None & $1127(51.1)$ & $222(50.8)$ & $3695(55.7)$ \\
\hline$\leq 6 \mathrm{~h}$ & $21(1.0)$ & $8(1.8)$ & $51(0.8)$ \\
\hline$>6$ but $<24 \mathrm{~h}$ & $47(2.1)$ & $15(3.4)$ & $137(2.1)$ \\
\hline$\geq 24 \mathrm{~h}$ & $1009(45.8)$ & $192(43.9)$ & $2744(41.4)$ \\
\hline Current smoker & $491(22.3)$ & $114(26.1)$ & $1980(29.9)$ \\
\hline Congestive heart failure & $573(26.0)$ & $133(30.4)$ & $1449(21.9)$ \\
\hline Previous PCI & $651(29.5)$ & $139(31.8)$ & $1878(28.3)$ \\
\hline Previous coronary bypass & $99(4.5)$ & $29(6.6)$ & $305(4.6)$ \\
\hline Previous valve surgery/procedure & $86(3.9)$ & $15(3.4)$ & $167(2.5)$ \\
\hline Preoperative angina pectoris & $1334(60.5)$ & $261(59.7)$ & $4208(63.5)$ \\
\hline Preoperative ejection fraction $(\%)$ - mean \pm SD & $48.8 \pm 13.7$ & $47.6 \pm 15.0$ & $49.8 \pm 13.0$ \\
\hline Left main disease & $638(29.0)$ & $118(27.0)$ & $1555(23.5)$ \\
\hline \multicolumn{4}{|l|}{ Operation } \\
\hline Elective & $1303(59.3)$ & $247(56.5)$ & $3801(57.4)$ \\
\hline Nonelective & $894(40.7)$ & $190(43.5)$ & $2826(42.6)$ \\
\hline Off-pump & $758(34.6)$ & $165(37.8)$ & $2625(39.6)$ \\
\hline On-pump & $1432(65.4)$ & $267(61.1)$ & $4002(60.4)$ \\
\hline Preoperative IABP & $342(15.5)$ & $82(18.8)$ & $708(10.7)$ \\
\hline
\end{tabular}


TABLE 2. Summary of outcomes by year

\begin{tabular}{|c|c|c|c|c|c|c|c|c|c|}
\hline Outcome & $\begin{array}{c}2004 \\
(n=968)\end{array}$ & $\begin{array}{c}2005 \\
(n=933)\end{array}$ & $\begin{array}{c}2006 \\
(n=914)\end{array}$ & $\begin{array}{c}2007 \\
(n=1104)\end{array}$ & $\begin{array}{c}2008 \\
(n=1970)\end{array}$ & $\begin{array}{c}2009 \\
(n=1848)\end{array}$ & $\begin{array}{c}2010 \\
(\mathbf{n}=1531)\end{array}$ & $\begin{array}{c}\text { Total } \\
(\mathbf{N}=\mathbf{9 2 6 8})\end{array}$ & $\begin{array}{c}P \\
\text { value }\end{array}$ \\
\hline \multicolumn{10}{|l|}{ New-onset AF incidence* } \\
\hline Unadjusted $-\mathrm{n}(\%)$ & $283(29.2)$ & $280(30.0)$ & $248(27.1)$ & $321(29.1)$ & $565(28.9)$ & $540(29.2)$ & $404(26.4)$ & $2641(28.5)$ & .40 \\
\hline Adjusted $-\% \dagger$ & 31.0 & 32.9 & 30.5 & 33.8 & 35.2 & 36.0 & 31.9 & 33.4 & .21 \\
\hline \multicolumn{10}{|c|}{ New-onset AF incidence according to STS data and definition } \\
\hline Unadjusted $-\mathrm{n}(\%)$ & $255(26.3)$ & $231(24.8)$ & $207(22.7)$ & $260(23.6)$ & $464(23.6)$ & $452(24.5)$ & $335(21.9)$ & $2204(23.8)$ & .22 \\
\hline Adjusted $-\% \dagger$ & 26.5 & 28.1 & 24.7 & 26.3 & 27.7 & 29.4 & 26.1 & 27.0 & .30 \\
\hline \multicolumn{10}{|c|}{ New-onset AF not identified in the STS data } \\
\hline Unadjusted - n (\%) & $28(2.9)$ & $49(5.3)$ & $41(4.5)$ & $61(5.5)$ & $101(5.1)$ & $88(4.8)$ & $69(4.5)$ & $437(4.7)$ & .45 \\
\hline Adjusted $-\% \dagger$ & 4.5 & 4.8 & 5.8 & 7.5 & 7.5 & 6.6 & 5.8 & 6.4 & .44 \\
\hline 30-d mortality (unadjusted) & $31(3.2 \%)$ & $14(1.5 \%)$ & $15(1.6 \%)$ & $10(0.9 \%)$ & $30(1.5 \%)$ & $23(1.2 \%)$ & $20(1.3 \%)$ & $143(1.5 \%)$ & .001 \\
\hline No AF & $15(2.2 \%)$ & $5(0.8 \%)$ & $6(0.9 \%)$ & $3(0.4 \%)$ & $11(0.8 \%)$ & $6(0.5 \%)$ & $8(0.7 \%)$ & $54(0.8 \%)$ & .002 \\
\hline $\begin{array}{l}\text { New-onset AF incidence according } \\
\text { to STS data and definition }\end{array}$ & $9(3.5 \%)$ & $6(2.6 \%)$ & $7(3.4 \%)$ & $4(1.5 \%)$ & $13(2.8 \%)$ & $17(3.8 \%)$ & $5(1.5 \%)$ & $61(2.8 \%)$ & .422 \\
\hline $\begin{array}{l}\text { New-onset AF not identified } \\
\text { in the STS data }\end{array}$ & $7(17.1 \%)$ & $3(5.3 \%)$ & $2(3.9 \%)$ & $3(4.4 \%)$ & $6(5.6 \%)$ & $0(0.0 \%)$ & $7(9.1 \%)$ & $28(6.2 \%)$ & .006 \\
\hline
\end{tabular}

$A F$, Atrial fibrillation; STS, Society of Thoracic Surgeons. *Any episode detected via continuous in-hospital ECG/telemetry monitoring and documented by a physician in the

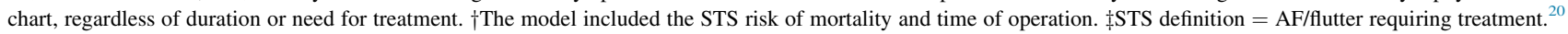

(reported for the most recent full year in the STS Adult Cardiac Surgery database) ${ }^{24}$

To determine the effect of the definition of post-CABG AF used (identified in the STS data vs not) on 30-day mortality, we used a GEE logistic model with 30-day mortality as the outcome variable and post-CABG AF (no AF, AF according to STS data, and AF not identified in the STS data) as the main predictor, with model covariates including the STS risk of mortality ${ }^{21}$ and time of operation, modeled using the approach and spline functions $\mathrm{s}^{22,23}$ described earlier. Model estimates were used to compute ORs, $95 \% \mathrm{CIs}$, and $P$ values. All analyses were performed using SAS 9.3 (SAS Institute, Inc, Cary, NC).

\section{RESULTS}

Table 1 shows the clinical and demographic characteristics of the study population by new-onset post-CABG AF status, with patients who had any episode of post-CABG AF detected via continuous in-hospital ECG/telemetry



FIGURE 1. Adjusted** probability of new-onset post-CABG AF by time. **The model included the STS risk of mortality and time of operation. $A F$, Atrial fibrillation; $C A B G$, coronary artery bypass grafting; $S T S$, Society of Thoracic Surgeons; $C I$, confidence interval. monitoring and documented by a physician in the patient's chart divided into those also identified as having AF in the STS data versus those missed in the STS data. Table 2 shows the unadjusted and adjusted incidence of post-CABG AF under each of these definitions by year, as well as unadjusted 30-day mortality by year. Overall, post-CABG AF incidence (adjusted for STS risk of mortality, time of operation, and interaction between $\mathrm{AF}$ and time of operation) was $33.4 \%$, including $27.0 \%$ identified in the STS data and $6.4 \%$ missed by the STS data. Significant differences in adjusted incidence of post-CABG AF were observed over time (Table 2 and Figure 1), and the STS data/definition systematically and significantly underestimated post-CABG AF (Figure 1).

In 2013, 147,600 isolated CABG surgeries were reported nationwide in the STS Adult Cardiac Surgery Database. ${ }^{24}$ The significant underestimation observed using the STS data and definition translates into $9600 \quad(95 \%$ CI, 9420-9780) undetected/missed cases of AF after isolated CABG in the United States each year.

The unadjusted 30-day mortality rate was $1.5 \%$ overall (143 deaths). Breaking it down by post-CABG AF status, the rate was $0.8 \%$ in the patients with no $\mathrm{AF}, 2.8 \%$ in the patients with AF identified in the STS data, and $6.4 \%$ in the patients with AF not identified in the STS data. Among patients with post-CABG AF, those not identified in the STS data had significantly higher risk-adjusted 30-day mortality (OR, 2.08; 95\% CI, 1.17-3.69) (Figure 2).

\section{DISCUSSION}

\section{Principal Findings}

Our results show that limiting the definition of post$\mathrm{CABG} \mathrm{AF}$ to episodes requiring treatment significantly 


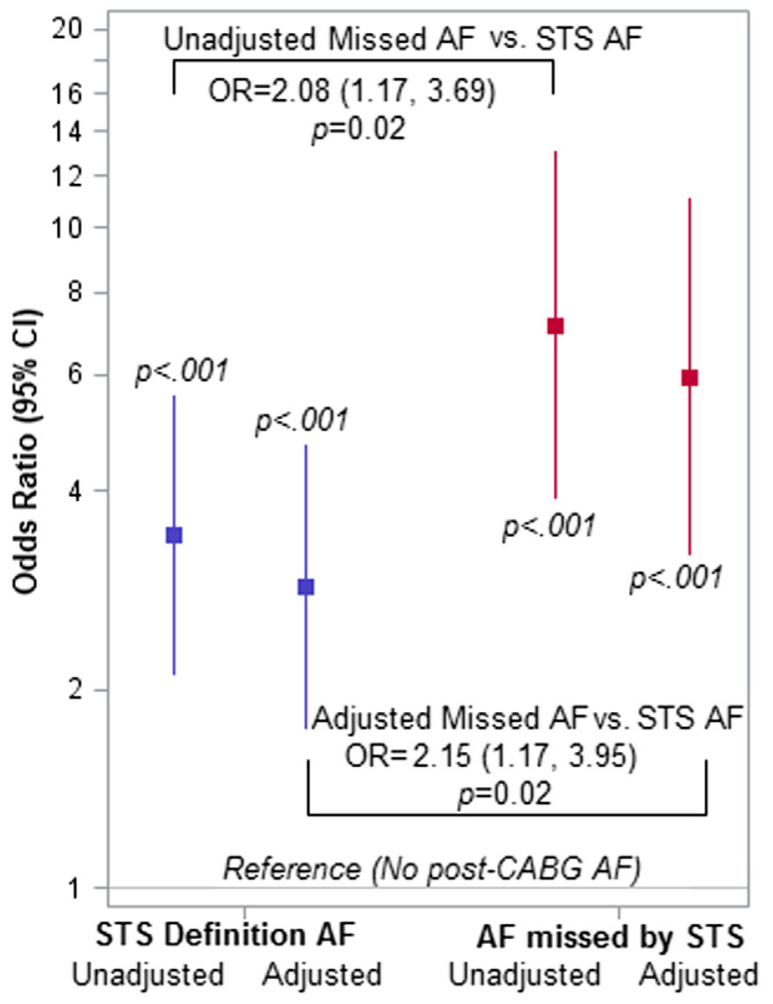

FIGURE 2. Unadjusted and adjusted** ORs for 30-day mortality. **Adjusted for the STS risk of mortality and time of surgery. AF, Atrial fibrillation; STS, Society of Thoracic Surgeons; $O R$, odds ratio; $C I$, confidence interval; $C A B G$, coronary artery bypass grafting.

underestimates the incidence of this serious complication of CABG. Although the unadjusted and risk-adjusted incidences of new-onset post-CABG AF we observed under both definitions were consistent with the range of $10 \%$ to $40 \%$ frequently cited for CABG, ${ }^{15,25,26}$ the results from the more inclusive definition $(33.4 \%$ after risk adjustment) indicate that true incidence is toward the high end of this range. Overall, the STS definition missed a risk-adjusted $6.4 \%$ of patients undergoing isolated CABG who developed new-onset post-CABG AF (an estimated 9600 US isolated CABG cases each year), a group our results show have a risk for 30 -day mortality that is significantly greater than the patients whose post-CABG AF is captured by the STS data and definition.

\section{Comparison With the Literature}

The patterns of comorbidities, age, body habitus, ejection fraction, and use of elective CABG in our study cohort are similar to those reported for isolated CABG cases from 2000 to 2009 in the national STS Adult Cardiac Surgery database,${ }^{27}$ indicating that our results are likely generalizable to the broader population of US patients undergoing CABG. We also saw similar patterns in the unadjusted operative mortality rate. ${ }^{27}$ With respect to trends over time in incidence of new-onset post-CABG AF, our results differ from the national findings that show a statistically significant increase in both the unadjusted incidence (from $19.8 \%$ in 2000 to $21.1 \%$ in $2009, P<.0001$ ) and the risk-adjusted incidence (from $20.0 \%$ in 2000 to $20.5 \%$ in $2009, P=.04) .{ }^{27}$ The national cohort also reported a lower risk-adjusted incidence $(\sim 20 \%)$ than the $33.4 \%$ (study definition) and $27.0 \%$ (STS definition) we observed. ${ }^{27}$ Although the difference from the former is partly explained by the different definitions, the same is not true for the latter. The STS Contemporary Analysis of Perioperative Cardiovascular Surgical Care (CAPS-Care) registry used a definition of postoperative AF much closer to our study definition ("any sustained AF that occurred in the postoperative period while hospitalized" ${ }^{28}$ ) and reported an unadjusted incidence of $28 \%$ for 2004 and $2005,{ }^{28}$ which is close to the $29.2 \%$ to $30.0 \%$ unadjusted incidence we observed for these years.

We found no previous studies in the literature that compared mortality between different definitions of post-CABG AF. To provide some context for judging the magnitude of the effect we observed, however, it is worth noting that the increased risk we observed for patients whose post-CABG AF was versus was not identified in the STS data was similar to that which has been reported for patients with post-CABG AF (defined as the documentation of $\mathrm{AF}$ of any duration at any time in the postoperative period on a physician assessment, on the basis of a rhythm strip or 12-lead ECG recording) versus no $\mathrm{AF}^{3}$

\section{Study Strengths and Weaknesses}

The study presented provides a unique combination of a large study population $(\sim 10,000$ patients $)$, limited to patients without a history of AF undergoing a single type of cardiac surgery (isolated $\mathrm{CABG}$ ), and comprehensive details of the clinical characteristics of all post-CABG AF events detected via continuous in-hospital ECG/telemetry monitoring and documented by a physician in the chart. To our knowledge, it is also the first study to directly assess the impact the choice of definition of AF has on the estimate of incidence of new-onset post-CABG AF, although several previous researchers have noted the inconsistencies between studies as one of the factors contributing to the wide range of incidences reported $^{14,15}$ or on the relationship between post-CABG AF and risk for adverse outcomes. Because we had access only to data regarding in-hospital incidence of post-CABG AF, there may have been additional patients who developed AF after discharge. Such numbers should be small, however, because onset of post-CABG AF is known to peak 2 to 3 days after surgery. ${ }^{29,30}$

Data were collected by abstracting information recorded in medical charts, and we cannot exclude the possibility of abstraction-related errors. Bias related to these errors should be minimal, however, because the abstraction 
processes were standardized and study personnel were trained for 1 month before starting the first formal abstraction. In the approximately $5 \%$ sample of charts we audited, inconsistencies or mistakes in the data collected related to AF-related events were identified in less than $0.5 \%$. Accordingly, in the overall study cohort, misclassification of new-onset post-CABG AF should be less than $0.05 \%$.

Our results show substantial inter-institutional variability in the unadjusted incidence of post-CABG AF. This site variability was accounted for in our analysis but will require further research to determine the extent to which it is caused by differences in patient characteristics (which we also accounted for in our adjusted analysis) versus institutional protocols related to the prevention and management of post-CABG AF.

\section{Meaning of the Study: Implications for Clinicians and Policymakers}

Our results show a significantly increased risk of 30-day mortality in patients with post-CABG AF that is missed by the STS definition and data. This is on top of the increased risk even the STS-identified post-CABG AF carries. As such, our results reveal an identifiable at-risk population who should be investigated first and foremost to determine whether their increased risk is being mediated by differences in monitoring and management from those patients whose $\mathrm{AF}$ is deemed to require treatment, and is thus identified in the STS data.

In addition to these direct and actionable implications of our study results, there are several indirect implications. Given the strong association between post-CABG AF and poorer survival, ${ }^{2,3,6-9}$ the underestimation of incidence that our results demonstrate with reliance on the STS definition could affect the balance of risks and benefits in a patient's treatment options. This will be particularly true if the increased risk we observed for 30-day mortality in patients whose post-CABG AF is being missed by the STS data carries over into increased risk for long-term outcomes. Currently, these patients are being grouped with the "no AF" patients, and so may be weakening the ability to observe true differences in risk between patients who do and do not develop post-CABG AF. There are also important implications for research studies investigating the prevention of AF or its impact on outcomes that rely on the STS Adult Cardiac Surgery database (or local/regional databases that apply the same definition). For example, in a study evaluating the effectiveness of a strategy such as perioperative B-blockers or amiodarone $^{10-12}$ to prevent post-CABG $\mathrm{AF}$, if a prophylactic strategy prevents episodes not requiring treatment better than it does those requiring treatment, applying the STS definition will underestimate its effectiveness, and conversely, should the prophylactic strategy have greater effect against $\mathrm{AF}$ episodes requiring treatment.
The STS Adult Cardiac Surgery database, which includes data for approximately $95 \%$ of the cardiac surgery programs in the United States, ${ }^{16}$ provides a valuable resource for many aspects of outcomes research in cardiac surgery. However, its reliance on a definition of postoperative AF dependent on whether treatment of the episode was deemed necessary compromises its utility for evaluations of strategies to prevent $\mathrm{AF}$ and for studies examining the impact of postoperative AF on other outcomes. It will also fail to identify approximately 9600 patients undergoing isolated $\mathrm{CABG}$ each year who may be at increased risk for the adverse outcomes associated with post-CABG AF and who might therefore benefit from more intensive follow-up after discharge. Therefore, we strongly urge the definition used by expanded to capture all documented events of post-CABG AF, regardless of duration or need for treatment.

\section{CONCLUSIONS}

Defining post-CABG AF as episodes requiring treatment significantly underestimates incidence of this complication and misses patients at significantly increased risk for mortality. Further research is needed to determine whether the increased risk for 30-day mortality that we observed in patients whose post-CABG AF was missed by the STS data and definition carries over into long-term outcomes, and whether it is mediated by differences in treatment and management. Such work will form only one part of the broader research needed to effectively identify patients at risk for and prevent development of post-CABG AF in the broader population of patients undergoing $\mathrm{CABG}$, but for those approximately 9600 US patients undergoing isolated CABG each year who develop post-CABG AF missed by the STS definition and who are currently carrying an increased risk of mortality, it could, nonetheless, make a meaningful difference in outcomes.

\section{Conflict of Interest Statement}

Dr Damiano reports grants and consulting fees from Atricure and lecture fees from LivaNova. Dr Thourani reports grants from Edwards Lifesciences, Abbott Vascular, Medtronic, and Boston Scientific, and personal fees from Edwards Lifesciences and Abbott Vascular. All other authors have nothing to disclose with regard to commercial support.

\section{References}

\footnotetext{
1. Soucier RJ, Mirza S, Abordo MG, Berns E, Dalamagas HC, Hanna A, et al. Predictors of conversion of atrial fibrillation after cardiac operation in the absence of class I or III antiarrhythmic medications. Ann Thorac Surg. 2001;72:694-8.

2. Filardo G, Hamilton C, Hebeler RF Jr, Hamman B, Grayburn P. New-onset postoperative atrial fibrillation following isolated coronary artery bypass graf surgery and long-term survival. Circ Cardiovasc Qual Outcomes. 2009;2:164-9.

3. Villareal RP, Hariharan R, Liu BC, Kar B, Lee VV, Elayda M, et al. Postoperative atrial fibrillation and mortality after coronary artery bypass surgery. J Am Coll Cardiol. 2004;43:742-8.
} 
4. Landymore RW, Howell F. Recurrent atrial arrhythmias following treatment for postoperative atrial fibrillation after coronary bypass operations. Eur J Cardiothorac Surg. 1991;5:436-9.

5. Rubin DA, Nieminski KE, Reed GE, Herman MV. Predictors, prevention, and long-term prognosis of atrial fibrillation after coronary artery bypass graft operations. J Thorac Cardiovasc Surg. 1987:94:331-5.

6. Bramer S, van Straten AH, Soliman Hamad MA, Berreklouw E, Martens EJ, Maessen JG. The impact of new-onset postoperative atrial fibrillation on mortality after coronary artery bypass grafting. Ann Thorac Surg. 2010;90:443-9.

7. El-Chami MF, Kilgo P, Thourani V, Lattouf OM, Delurgio DB, Guyton RA, et al New-onset atrial fibrillation predicts long-term mortality after coronary artery bypass graft. J Am Coll Cardiol. 2010;55:1370-6.

8. Mariscalco G, Klersy C, Zanobini M, Banach M, Ferrarese S, Borsani P, et al. Atrial fibrillation after isolated coronary surgery affects late survival. Circulation. 2008;118:1612-8.

9. Philip F, Becker M, Galla J, Blackstone E, Kapadia SR. Transient post-operative atrial fibrillation predicts short and long term adverse events following CABG. Cardiovasc Diagn Ther. 2014;4:365-72.

10. National Quality Forum. 0236: Coronary Artery Bypass Graft (CABG): Preoperative Beta-Blocker in Patients with Isolated CABG Surgery. 2015. Available at: http://www.qualityforum.org/ProjectTemplateDownload.aspx? SubmissionID=428. Accessed June 30, 2017.

11. National Quality Forum. 0127: Preoperative Beta Blockade. 2015. Available at: http://www.qualityforum.org/QPS/Download.aspx?IsDynamicMEF=true \& SubmissionID=1175. Accessed June 30, 2017.

12. Hillis LD, Smith PK, Anderson JL, Bittl JA, Bridges CR, Byrne JG, et al. 2011 ACCF/AHA Guideline for Coronary Artery Bypass Graft Surgery. A report of the American College of Cardiology Foundation/American Heart Association Task Force on Practice Guidelines. Developed in collaboration with the American Association for Thoracic Surgery, Society of Cardiovascular Anesthesiologists, and Society of Thoracic Surgeons. J Am Coll Cardiol. 2011;58:e123-210.

13. Authors/Task Force Members, Windecker S, Kolh P, Alfonso F, Collet JP, Cremer J, Falk V, et al. 2014 ESC/EACTS Guidelines on myocardial revascularization: The Task Force on Myocardial Revascularization of the European Society of Cardiology (ESC) and the European Association for Cardio-Thoracic Surgery (EACTS)Developed with the special contribution of the European Association of Percutaneous Cardiovascular Interventions (EAPCI). Eur Heart J. 2014;35:2541-619.

14. Maisel WH, Rawn JD, Stevenson WG. Atrial fibrillation after cardiac surgery. Ann Intern Med. 2001;135:1061-73.

15. Bessissow A, Khan J, Devereaux PJ, Alvarez-Garcia J, Alonso-Coello P. Postoperative atrial fibrillation in non-cardiac and cardiac surgery: an overview. J Thromb Haemost. 2015;13(Suppl 1):S304-12.

16. Jacobs JP, Shahian DM, He X, O'Brien SM, Badhwar V, Cleveland JC Jr, et al. Penetration, completeness, and representativeness of The Society of Thoracic Surgeons Adult Cardiac Surgery Database. Ann Thorac Surg. 2016; 101:33-41.

17. LLaPar DJ, Speir AM, Crosby IK, Fonner E Jr, Brown M, Rich JB, et al. Postoperative atrial fibrillation significantly increases mortality, hospital readmission, and hospital costs. Ann Thorac Surg. 2014;98:527-33.
18. BrinBrinkman W, Herbert MA, O’Brien S, Filardo G, Prince S, Dewey T, et al Preoperative beta-blocker use in coronary artery bypass grafting surgery: national database analysis. JAMA Intern Med. 2014;174:1320-7.

19. Magee MJ, Herbert MA, Dewey TM, Edgerton JR, Ryan WH, Prince S, et al Atrial fibrillation after coronary artery bypass grafting surgery: development of a predictive risk algorithm. Ann Thorac Surg. 2007;83:1707-12.

20. Society of Thoracic Surgeons. STS Adult Cardiac Surgery Database Data Specifications Version 2.81. 2014. Available at: http://www.sts.org/sites/default/files/ documents/STSAdultCVDataSpecificationsV2_81.pdf. Accessed June 30, 2017.

21. Shahian DM, O'Brien SM, Filardo G, Ferraris VA, Haan CK, Rich JB, et al. The Society of Thoracic Surgeons 2008 cardiac surgery risk models: part 1-coronary artery bypass grafting surgery. Ann Thorac Surg. 2009;88:S2-22.

22. Harrell FE Jr. Regression Modeling Strategies: With Application to Linear Models, Logistic Regression, and Survival Analysis. New York: Springer-Verlag; 2001.

23. Filardo G, Hamilton C, Hamman B, Ng HK, Grayburn P. Categorizing BMI may lead to biased results in studies investigating in-hospital mortality after isolated CABG. J Clin Epidemiol. 2007;60:1132-9.

24. Society of Thoracic Surgeons. STS Adult Cardiac Surgery Database-Period Ending 09/30/2014 Executive Summary Contents. Available at: http://www.sts.org/sites/ default/files/documents/2014Harvest4_ExecutiveSummary.pdf. Accessed May 19, 2015

25. Sun DM, Yuan X, Wei H, Zhu SJ, Zhang P, Zhang SJ, et al. Impaired myocardium energetics associated with the risk for new-onset atrial fibrillation after isolated coronary artery bypass graft surgery. Coron Artery Dis. 2014;25: 224-9.

26. Amin H, Greer DM. Perioperative stroke. In: Torbey MT, Selim MH, eds. The Stroke Book. Cambridge: Cambridge University Press; 2013:257-68.

27. ElBardissi AW, Aranki SF, Sheng S, O’Brien SM, Greenberg CC, Gammie JS Trends in isolated coronary artery bypass grafting: an analysis of the Society of Thoracic Surgeons adult cardiac surgery database. J Thorac Cardiovasc Surg. 2012;143:273-81.

28. Steinberg BA, Zhao Y, He X, Hernandez AF, Fullerton DA, Thomas KL, et al. Management of postoperative atrial fibrillation and subsequent outcomes in contemporary patients undergoing cardiac surgery: insights from the Society of Thoracic Surgeons CAPS-Care Atrial Fibrillation Registry. Clin Cardiol. 2014;37:7-13.

29. Place DG, Peragallo RA, Carroll J, Cusimano RJ, Cheng DC. Postoperative atrial fibrillation: a comparison of off-pump coronary artery bypass surgery and conventional coronary artery bypass graft surgery. J Cardiothorac Vasc Anesth. 2002; $16: 144-8$.

30. Zaman AG, Archbold RA, Helft G, Paul EA, Curzen NP, Mills PG. Atrial fibrillation after coronary artery bypass surgery: a model for preoperative risk stratification. Circulation. 2000;101:1403-8.

Key Words: atrial fibrillation, coronary artery bypass grafting, incidence, postoperative complication arrhythmia, 30-day mortality

Readers who found these articles interesting may also like to read the following papers found in recent and future issues of our sister publications, Seminars in Thoracic and Cardiovascular Surgery and Operative Techniques in Thoracic and Cardiovascular Surgery!

\section{Acquired: Arrhythmias}

Original Submission: Mid-Term Performance of Bipolar Radiofrequency Ablation for Isolated Atrial Fibrillation Through a Right Minithoracotomy. Giuseppe Nasso. Semin Thoracic Surg 2017: In press.

Original Submission: Results of Cryoablation for Atrial Fibrillation Concomitant With Video-Assisted Minimally Invasive Mitral Valve Surgery. Giovanni Marchetto. Semin Thoracic Surg 2016;8(2):271-280. 